\title{
ZnO nanorods grown on ZnSe particles by the Chemical Vapor Deposition Method
}

\author{
Chongfeng Guo ${ }^{1}$, Wallace C. H. Choy ${ }^{1 *}$, Y.B. Leung ${ }^{1}$, K.W. Cheah ${ }^{2}$, Yueping Fang ${ }^{3}$ \\ ${ }^{1}$ Department of Electrical and Electronic Engineering, the University of Hong Kong, \\ Pokfulam Road, Hong Kong, China. \\ ${ }^{2}$ Department of Physics, Hong Kong Baptist University, Kowloon, Hong Kong, China. \\ ${ }^{3}$ School of Chemistry and Chemical Engineering, Guangxi Normal University, Guilin, \\ Guangxi, 541004, P.R. China.
}

Keywords: $\mathrm{ZnO}$ nanorods, ZnSe micro-particles, chemical vapor deposition, synthesis mechanism, photoluminescence

PACS no.: 73.21.-b, 78.55.Et, 61.10.Nz, 61.46.+w, 68.65.-k

* Author to whom correspondence should be addressed

W.C. H. Choy

Department of Electrical and Electronic Engineering

The University of Hong Kong,

Hong Kong SAR, P. R. China

Tel and Fax:

Electronic mail: chchoy@eee.hku.hk 


\begin{abstract}
:
A novel structure of $\mathrm{ZnO}$ nanorods on microsized $\mathrm{ZnSe}$ particles has been prepared through a chemical vapor deposition (CVD) technique using $\mathrm{Zn}$ and Se powders as the sources. The dimension of the nanorods can be controlled by adjusting the growth temperature, time and the $\mathrm{Zn}$ :Se ratio. Through the investigation of the effects of synthesis time and $\mathrm{Zn}: \mathrm{Se}$ ratio on the formation of $\mathrm{ZnO}$ nanorods on $\mathrm{ZnSe}$ microparticles, it is proposed that the synthesis of the $\mathrm{ZnO}-\mathrm{ZnSe}$ structures involves a twostage formation. The growth of $\mathrm{ZnO}$ nanorods can be described by $\mathrm{VS}$ mechanism. The photoluminescence (PL) of the $\mathrm{ZnO}-\mathrm{ZnSe}$ structures has also been studied.
\end{abstract}




\section{Introduction}

The direct wide band-gap semiconductors such as most of the $\mathrm{Zn}$ and $\mathrm{Cd}$ based II-VI compound semiconductors are of the great interest for use in blue and ultraviolet (UV) optical devices [1,2]. Zn-based II-VI compound semiconductors have already been utilized in a wide range of applications. For instance, $\mathrm{ZnO}$ has been used for solar cell windows, transparent conductive films, catalysis, gas sensors and short-wave optics $[3,4]$. ZnSe has been applied for use in saturable-absorber Q switch, blue-green laser diode, modulated waveguide and blue-ultraviolet photodetector [5]. Meanwhile, intense efforts have been put into studying quasi-one-dimensional II-VI compound semiconductors during the past decades because of their unique quantum properties and their potential for nanoscale electronic and optoelectronic integrated devices. Many active researches have been focused on the synthesis of 1-D II-VI compound semiconductors through different methods, such as solvothermal route[6], laser-assisted catalytic growth[7], surfactantassisted chemistry method [8,9], metalorganic chemical vapor deposition (MOCVD) [10] and chemical vapor deposition (CVD) method [11]. Among these methods, CVD method is the most popular one.

Here we present a novel structure of $\mathrm{ZnO}$ nanorods grown on the surface of micrometersized $\mathrm{ZnSe}$ particles. The synthesis is based on chemical vapor deposition (CVD) of $\mathrm{Zn}$ and Se powders under controlled conditions without the use of catalyst. The effects of the residual oxygen in the reactor on the synthesis of nanorods will be investigated through changing the usage of the Se powder and adding the carbon powder in the sources. We also study the effects of the growth time and temperature. The chemical composition, structural and optical properties of the sample were also investigated using 
scanning electron microscopy (SEM), high resolution transmission electron microscopy (HRTEM), X-ray diffraction (XRD), and photoluminescence (PL).

\section{Experimental procedures}

$\mathrm{ZnO}$ nanorods grown on the surface of $\mathrm{ZnSe}$ grain particles were prepared by thermal evaporating $\mathrm{Zn}$ and Se powders in $\mathrm{N}_{2}$ filled chamber without the presence of catalyst. The furnace setup used in this study is illustrated in Fig. 1. A quartz tube was set horizontally inside the furnace. Zinc and selenium powders in two separate alumina crucibles were placed at different temperature zones inside the quartz-tube chamber. The crucible with selenium was placed nearer to the gas input at a lower temperature zone while zinc source was placed at the central region of the furnace of a higher temperature

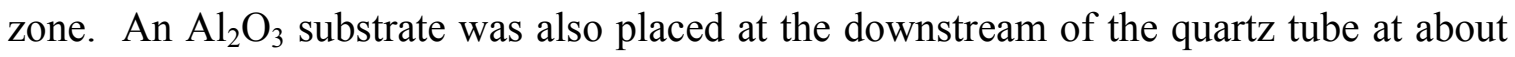
$2.5 \mathrm{~cm}$ away from the crucible filled with $\mathrm{Zn}$ powder. Then the tube was pumped down to a pressure of about $10^{-2}$ Torr. The total pressure was maintained at 300 Torr during the whole fabrication process when $\mathrm{N}_{2}$ gas was introduced into the quartz tube at a constant flow rate of $150 \mathrm{sccm}$ (standard cubic centimeter per minute). After the growth process, the furnace was gradually cooled down to room temperature by turning off the power supply. A layer of yellow colored sample was formed on the inner-wall of the crucible of zinc powder.

The sample scrapped from the inner-wall was characterized and analyzed by scanning electron microscopy (SEM, Jeol JEM 2000FX), high-resolution transmission electron microscopy (HRTEM, Philips Tecnai 20), energy dispersive X-ray spectroscopy (EDS), X-ray diffraction (XRD, Rigakau, D/Max with $\mathrm{Cu}$ Ka radiation). The specimens for TEM 
were prepared by mixing the synthesized products in ethanol and dispersing them in an ultrasonic bath for $20 \mathrm{~min}$. The resulting mixtures were dropped onto a TEM grid for measurement. Photoluminescence (PL) at the $20 \mathrm{~K}$ was performed in a cryostat. The excitation source is He-Cd laser with a wavelength of $325 \mathrm{~nm}$. During the measurement, the power of the laser beam at the sample holder was kept at about $0.4 \mathrm{~mW}$.

\section{Results and discussion}

The X-ray diffraction (XRD) pattern of the yellow products prepared at $650^{\circ} \mathrm{C}$ and the ratio of $\mathrm{Zn}: \mathrm{Se}=1: 1$ in weight is shown in Fig.2. A set of diffraction peaks with strong intensity can be indexed as those from the known zinc-blende structure of $\mathrm{ZnSe}$, with a lattice constant of $a=0.5675 \mathrm{~nm}$. This matches very well to the data in the literature within a small experimental error (JCPDS, file No.:37-1463; $\mathrm{a}=0.5668 \mathrm{~nm}$; error is $0.12 \%$ ). The results indicate that the main component of the products is zinc-blende cubic $\mathrm{ZnSe}$ while the details of the chemical composition of synthesized materials will be further investigated by HRTEM, EDS and SAED.

The as-synthesized samples are first analyzed by scanning electron microscopy (SEM) to determine the relationship between the growth temperature and their morphologies. Fig.3 (a), (b), (c) and (d) show the typical FESEM images of as-prepared samples grown at different temperatures $550^{\circ} \mathrm{C}, 600^{\circ} \mathrm{C}, 650^{\circ} \mathrm{C}$ and $700^{\circ} \mathrm{C}$, respectively. Particles with different diameters (up to micrometer) and irregular shapes are observed, and the nanorods randomly grow on the surface of the particles. It is interesting to note that the morphology shows a wool-ball-like structure in Fig.3 (b) and (c). The majority of the wool-ball-like structures are composed of two parts, micron-sized particles and nanorods 
or nanowires which are grown around the surface of the particles. Diameter of the nanorods mainly ranges from 15 to $100 \mathrm{~nm}$ and their length extends from $100 \mathrm{~nm}$ to $1 \mu \mathrm{m}$. The nanorods generally exhibit a hexagonal cross-section as displayed in the inset of Fig.3(c). The amount of nanorods can be controlled by tuning the growth temperature. As shown in Fig.3, a large amount of nanorods are obtained at the temperature range of $600-650^{\circ} \mathrm{C}$.

The influence of the growth time on the nanostructures has also been investigated using the synthesis time of $15,30,60$ and $120 \mathrm{~min}$ at the temperature of $650^{\circ} \mathrm{C}$ when the other growth parameters are kept constant. The SEM images of Fig. 4 and Fig.3(c) illustrate the formation of the nanostructures as a function of the growth time. Nanometer-sized seeds are first grown on the surfaces of ZnSe particles as shown in Fig.4a when the growth time is 15 min. Meanwhile, some facets of the particles are still smooth and clean. This implies that nanosized seeds begin to grow on the surface of ZnSe particle after the formation of $\mathrm{ZnSe}$ particle. By increasing the synthesis time to 30min, nanorods are obtained as shown in Fig.4b. The lengths of the nanorods extend to about $1 \mu \mathrm{m}$ when the growth time is increased to $60 \mathrm{~min}$ as shown in Fig.3c. When the growth time is further increased to $120 \mathrm{~min}$ (see Fig.4c), the nanorods on the surface of the particle become longer and some scattered nanowires are obtained as shown in the inset of Fig. 4c. Their diameter and length can be up to about $150 \mathrm{~nm}$ and several micrometers, respectively. As a consequence, it is believed that the formation of the novel structure can be described by a two-stage process. The first stage is the growth of the particle and the second stage is the nucleation and growth of the nanorods on the surfaces of the micro-particles. When 
the growth time is short, seeds are found on the particles. With the increase of the growth time, the nanorods are formed. The length and diameter of the nanorods increase with the growth time. The formation mechanism of the nanorods on particles will be discussed in detail later.

As shown in Fig. 5(a) and (b), the EDS results reveal that the products contain nanosized $\mathrm{ZnO}$ rods and microsized $\mathrm{ZnSe}$ particles. Fig. 5(d) shows a TEM image of nanorods on the surface of a microparticle, revealing the representative morphology of the sample. The average diameter of the $\mathrm{ZnO}$ nanorods is around $20 \mathrm{~nm}$. The HRTEM image shown in Fig.5(c) shows the atomic structure of a single nanorod. The continuous lattice fringes indicate that the $\mathrm{ZnO}$ nanorod is of a single crystal. Its growth direction is along [0001] and the spacing between two fringes is $0.52 \mathrm{~nm}$. The Fourier transform of the HRTEM image is given in the inset of Fig. 5(c).

In the experiment, $\mathrm{Zn}$ and Se powders are used as the source materials and pure nitrogen is used as the carrier gas. The oxygen for the formation of $\mathrm{ZnO}$ nanorods is from the source powders, residual oxygen and moisture in the furnace setup [12-14]. To study the effect of oxygen in the growth of $\mathrm{ZnO}$ nanorods, a series of experiments are conducted by adjusting the weight ratio of $\mathrm{Zn}: \mathrm{Se}$ from 2:1 to 1:5 while keeping the other parameters the same. The growth time and temperature are $60 \mathrm{~min}$ and $650^{\circ} \mathrm{C}$ respectively. Fig. 6(a) to (c) are the FESEM images of the as-synthesized sample with weight ratios of $\mathrm{Zn} / \mathrm{Se}$ corresponding to the 2:1, 1:1 and 1:5, respectively. With the decrease of $\mathrm{Zn}: \mathrm{Se}$ ratio by increasing the weight of Se source and maintaining the weight of $\mathrm{Zn}$ constant, the length 
of $\mathrm{ZnO}$ nanorods grown on the surface of $\mathrm{ZnSe}$ particles becomes shorter and shorter. When the $\mathrm{Zn}:$ Se ratio $=2: 1$, the lengths of the nanorods can be over 1 micrometer as shown in Fig.6(a). The length of the nanorods reduces in the case of 1:1 ratio (see Fig.6b) and becomes seeds with only a few nanometer long on the surface of the ZnSe particles when $\mathrm{Zn}$ :Se ratio is 1:5 as shown in Fig.6(c). It is worth to note that some Se powder remains in the crucible for the case of 1:5 while there is no Se powder left in the crucible after the reaction for the cases of 2:1 and 1:1. The results show that the formation of nanorods depends on the partial pressure of selenium and oxygen. During the initial stage of the synthesis, an abundant of selenium source is present and its partial pressure is high, the conditions favor the formation of $\mathrm{ZnSe}$ particles. In the later stage of the synthesis, the partial pressure of selenium reduces, especially when the Se source is almost completely evaporated. The partial pressure of oxygen becomes significant and $\mathrm{ZnO}$ nanorods are formed. The results further support the two-stage formation theory of $\mathrm{ZnO}$ nanorods on $\mathrm{ZnSe}$ microparticles discussed previously. We have also placed some active carbon powder in the reactor to minimize the residual oxygen in the reactor. The result, as expected, is that no $\mathrm{ZnO}$ nanorod is formed on the surface of the $\mathrm{ZnSe}$ particle as shown in Fig.6(d).

From the effects of synthesis time and $\mathrm{Zn:Se}$ weight ratio as discussed previously, we postulate that the growth of the novel $\mathrm{ZnO}-\mathrm{ZnSe}$ structure can be described by a twostage process. The first stage is the growth of $\mathrm{ZnSe}$ particle. At the synthesis temperature of $550^{\circ} \mathrm{C}$ to $700^{\circ} \mathrm{C}$, vapor phase $\mathrm{Zn}$ and Se atoms encounter each other, they undergo a condensation reaction leading to the formation of single-crystalline nuclei of 
ZnSe. The ZnSe nuclei have a high surface energy and continuously undergo surface growth reaction by interacting with gaseous precursors. The $\mathrm{ZnSe}$ particles coagulate together on the inner and outer walls of the $\mathrm{Zn}$ filled crucible, the $\mathrm{Al}_{2} \mathrm{O}_{3}$ downstream substrate and the surface of the quartz tube. The growth of $\mathrm{ZnSe}$ particles will diminish when the selenium source is almost completely evaporated and the selenium partial pressure decreases to a certain level.

It should be noted that by comparing Fig.7(a) and Fig.7(b), we also find that the average size of ZnSe particle collected from inner-wall was larger than that from the outer-wall of the crucible or from the $\mathrm{Al}_{2} \mathrm{O}_{3}$ substrate in the downstream of the reactor, which is in good agreement with the result of E. M Gavrushchuk [15] that fine-grained powders are obtained in the reagents with a lower vapor composition.

The second stage is the growth of the nanorods. The metal-catalytic vapor-liquid-solid (VLS) process is one of the mechanisms to account for the growth of 1-D nanorods or nanowires. For metal-catalytic VLS, the growth mechanism typically involves a liquid metal catalytic particle located at the tip of the nanowires $[16,17]$. In our experiment, no metal catalyst is used and no alloy particle is observed at the tips of the nanorods. Therefore, the metal-catalytic VLS mechanism can be ruled out as the growth mechanism in our work. Our results show that $\mathrm{ZnO}$ nanorods on the $\mathrm{ZnSe}$ particles (see Fig.7a) can only be collected from the inner-wall of the crucible filled with $\mathrm{Zn}$ where the partial pressure of $\mathrm{Zn}$ is very high. The $\mathrm{ZnSe}$ particles collected from the outer-wall of the crucible, the alumina substrate in the downstream of the reactor (inset of Fig.7b) and the 
wall of quartz tube do not have $\mathrm{ZnO}$ nanorod. Therefore, we can conclude that high $\mathrm{Zn}$ partial pressure plays an important role in the formation of $\mathrm{ZnO}$ nanorods. The high local $\mathrm{Zn}$ partial pressure in the $\mathrm{Zn}$ powder filled crucible leads to super-saturation and the formation of liquid droplets of $\mathrm{Zn}$ on the surface of $\mathrm{ZnSe}$ particles. When the gaseous $\mathrm{Se}$ atoms diminish due to the complete evaporation of the Se source, the $\mathrm{Zn}$ vapor reacts with the gas-phase oxygen from the chamber to generate $\mathrm{ZnO}$ nanostructures. Consequently, the synthesis of the $\mathrm{ZnO}$ nanorods can be considered as a VS process [18].

Figure 8 illustrates the photoluminescence (PL) spectra of the as-prepared sample with the $\mathrm{Zn} / \mathrm{Se}$ ratio of 1:5, 1:2 and 1:1, at $20 \mathrm{~K}$. There are three emission bands present in the PL spectra of the samples with 1:1 and 1:2 Zn/Se ratios (Fig.8c and b), including a strong orange emission at around $600 \mathrm{~nm}$ and a small blue peak at about $462 \mathrm{~nm}$ as well as a weak but resoluble blue-green peak at around $500 \mathrm{~nm}$. The emission at around $462 \mathrm{~nm}$ is usually attributed to the donor-acceptor pair transition of $\mathrm{ZnSe}$ [19]. The strong orange emission at about $600 \mathrm{~nm}$ is associated with the vacancies of $\mathrm{Zn}$ in $\mathrm{ZnSe}$. This emission band is often observed in bulk $\mathrm{ZnSe}$, which is interpreted as a well known 'self-activated' luminescence in II-VI compounds due to the recombination of shallow donor-deep acceptor pairs [20]. As the other weak blue-green emission at around 500nm, it has been reported in [21] and may be due to the effects of the residual pressure of $\mathrm{H}_{2} \mathrm{O}$ and $\mathrm{O}_{2}$. However, we cannot find the near band edge UV emission at around $375 \mathrm{~nm}$ of the free excitonic emission of $\mathrm{ZnO}$ nanorods which is usually very sharp and strong [22]. The possible reason is that the emission at around $375 \mathrm{~nm}$ is absorbed by the $\mathrm{ZnSe}$ particle because the absorption region of $\mathrm{ZnSe}$ ranges from $325 \mathrm{~nm}$ to $425 \mathrm{~nm}$ [23]. On the other 
hand, the relative peak intensity of emission at $600 \mathrm{~nm}\left(\mathrm{I}_{600}\right)$ becomes weaker comparing with that of $462 \mathrm{~nm}\left(\mathrm{I}_{462}\right)$ when the $\mathrm{Zn}$ :Se ratio is changed from 1:1 to 1:9. The ratio of $\mathrm{I}_{600} / \mathrm{I}_{462}$ is about $10: 1,3: 1$ and 1:9 when the $\mathrm{Zn}:$ Se ratio increases from 1:1 to $1: 2$ and then 1:9, respectively, which indicates that the density of defects in ZnSe particle becomes smaller with the increasing Se usage in the experiment.

\section{Conclusion}

In conclusion, we have fabricated single-crystal $\mathrm{ZnO}$ nanorods on the surface of microsized ZnSe particles by CVD method using $\mathrm{Zn}$ and Se as the sources. The SEMs images show that the formation of $\mathrm{ZnO}$ nanorods can be controlled by synthesis time, temperature and amount of the sources. HRTEM reveals that the nanorods grow along the [0001] direction and are single crystals. Since the $\mathrm{ZnO}$ nanorods on $\mathrm{ZnSe}$ particles can only be collected from the inner-wall of the crucible filled with $\mathrm{Zn}$ source at which the partial pressure of $\mathrm{Zn}$ is high, the partial pressure of $\mathrm{Zn}$ plays an important role in the formation of the $\mathrm{ZnO}$ nanorods. The growth of the $\mathrm{ZnO}$ nanorods can be described as a VS mechanism. Through the investigation of the effects of growth temperature and the weight ratio of $\mathrm{Zn}: \mathrm{Se}$ on the formation of the novel $\mathrm{ZnO}-\mathrm{ZnSe}$ structures, we postulate that the synthesis process involves two stages which are (1) the formation of $\mathrm{ZnSe}$ microparticles followed by (2) the formation of $\mathrm{ZnO}$ nanorods on $\mathrm{ZnSe}$ particles. PL spectra of samples with different ratios of $\mathrm{Zn}: \mathrm{Se}$ at $20 \mathrm{~K}$ have been investigated. The defeats in ZnSe particles reduce with the increasing Se usage in the experiment. 


\section{Acknowledgement}

The authors would like to acknowledge the support of UDF grant and seed funding of the University of Hong Kong. Dr. Yuk would like to acknowledge the support of the small project funding the University of Hong Kong. The authors would like to thank for the technical assistance of Mr. Y.B. Leung and C.S. Cheung. 


\section{References}

[1] J. Q. Hu and Y. Bando, Appl. Phys. Let. 82 1401-1403 (2003).

[2] J. A. Garcia, A. Remon, A. Zubiaga, V. Munoz-Sanjose, C. Martinez-Tomas, Phys. Stat. Sol. A 194 338-341 (2002).

[3] Z. Wang, X. Qian, J. Yin, Z. Zhu, Langmuir 20 3441-3448 (2004).

[4] W. W. Wang, Y. Zhu, Chem. Let. 33 988-1000 (2004).

[5] R. Lv, C. Cao, H. Zhai, D. Wang, S. Liu, H. Sun, Solid State Commun. 130 241-243 (2004)

[6] W. Wang, Y. Geng, P. Yan, F. Liu, Y. Xie, Y. Qian, Inorg. Chem. Commun. 2 83-85 (1999)

[7] X. Duan, F and C. M. Lieber, Adv. Mat. 12 298-302 (2000)

[8] B. Ludolph, M. A. Malik, P. O’Brien, N. Revaprasadu, Chem. Commun. 171849 1851 (1998.)

[9] L. Guo, Y. Ji, H. Xu, Z. Wu, P. J. Simon, J. Mat. Chem. 13 754-766 (2003)

[10] X. T. Zhang, Z. Liu, K. M. Ip, Y. P. Leung, Q. Li, S. K. Hark, J. Appl. Phys. 95 $5752-5755(2004)$

[11] S. Y. Bae, H. W. Seo, J. Park, J.Phys. Chem. B 108 5206-5210 (2004)

[12] S. C. Lyu, O. H. Cha, E. K. Suh, H. Ruh, H. J. Lee, C. Lee, J Chem. Phys. Lett. 367 $136-138(2003)$

[13] Y. Dai, Y. Zhang, Q. K. Li, C. W. Nan, Chem. Phys. Lett. 358 83-85 (2002)

[14] T. Y. Kim, J. Y. Kim, S. H. Lee, H. W. Shim, Syn Metals 144 61-68 (2004)

[15] E. M. Gavrshchuk, Inorg. Mat. 39 883-899 (2003)

[16] Z. Dai, Z. Pan, Z. Wang, Adv. Function. Mat. 13 9-24 (2003) 
[17] Y. Ding, P. Gao, Z. Wang, J. Am, Chem. Soc. 126 2066-2072 (2004)

[18] H. Y. Dang, J. Wang and S. S. Fan, Nanotech. 14 738-741 (2003)

[19] P. Yu, M, Cardona, in Fundamentals of Semiconductors, Physics and Materials Properties, Springer, Berlin, 159 (1996).

[20] S. Fujita, H. Minmoto, T. Naguchi, J. Appl. Phys. 50 1079-1087 (1979)

[21] Z. L. Wang, J. Phys.:Condens. Mat. 16 R829-R858 (2004)

[22] W. Stutius, J. Crystal Growth 59 1-9 (1982)

[23] C. Ye, X. Fang, Y. Wang, P. Yan, J. Zhao, L. Zhang, Appl. Phys. A 79 113-115 (2004) 


\section{Captions}

Fig.1 Schematic diagram of the experimental apparatus used in the growth of $\mathrm{ZnO}$ ZnSe structures.

Fig.2 XRD pattern of the sample prepared at $650^{\circ} \mathrm{C}$ for $60 \mathrm{mins}$. The ratio of $\mathrm{Zn}: \mathrm{Se}$ is about $1: 1$.

Fig.3 FE-SEM images of $\mathrm{ZnO}$ nanorods or nanowires grown on the surface of $\mathrm{ZnSe}$ particles at various temperatures (a) $550^{\circ} \mathrm{C}$, (b) $600^{\circ} \mathrm{C}$, (c) $650^{\circ} \mathrm{C}$, and (d) $700^{\circ} \mathrm{C}$ for $60 \mathrm{mins}$ with the $\mathrm{Zn}$ :Se ratio of 1:1.

Fig.4 FE-SEM of sample prepared at $650^{\circ} \mathrm{C}$ with different growth time: (a) $15 \mathrm{mins}$, (b) 30mins, (c) 120mins. The ratio of $\mathrm{Zn}: \mathrm{Se}$ is 1:1.

Fig.5 (a) EDS of nanorods, corresponding to circle A in figure (d), (b) EDS of particle, corresponding to circle $B$ in figure (d), (c) HRTEM image of nanorods with the growth direction of [0001]. The inset is the corresponding Fourier transform, (d) The TEM image of the sample prepared at $650^{\circ} \mathrm{C}$ for $60 \mathrm{mins}$. The ratio of $\mathrm{Zn}: \mathrm{Se}$ is about $1: 1$.

Fig.6 FE-SEM image of sample prepared at $650^{\circ} \mathrm{C}$ for 60 mins with different $\mathrm{Zn}$ :Se ratio: (a) 2:1, (b) 1:1, (c) 1:5, (d) mixing carbon with Zn. The other parameters are kept constant.

Fig.7 FE-SEM image of sample collected from the inner-wall of crucible and the $\mathrm{Al}_{2} \mathrm{O}_{3}$ substrate in the downstream of the $\mathrm{Zn}$ crucible. The sample is prepared at $650^{\circ} \mathrm{C}$ for $60 \mathrm{mins}$ and the ratio of $\mathrm{Zn}: \mathrm{Se}$ is $1: 1$.

Fig.8 PL of the sample prepared at $650^{\circ} \mathrm{C}$ for $60 \mathrm{~min}$ with different $\mathrm{Zn}$ :Se ratios at $20 \mathrm{~K}$ temperature: (a) 1:5, (b) 1:2, (c):1:1. 
Fig.1 Schematic diagram of the experimental apparatus used in this work.




Fig. 2 XRD pattern of the sample prepared at $650^{\circ} \mathrm{C}$ for $60 \mathrm{mins}$. The ratio of $\mathrm{Zn}: \mathrm{Se}$ is about $1: 1$.

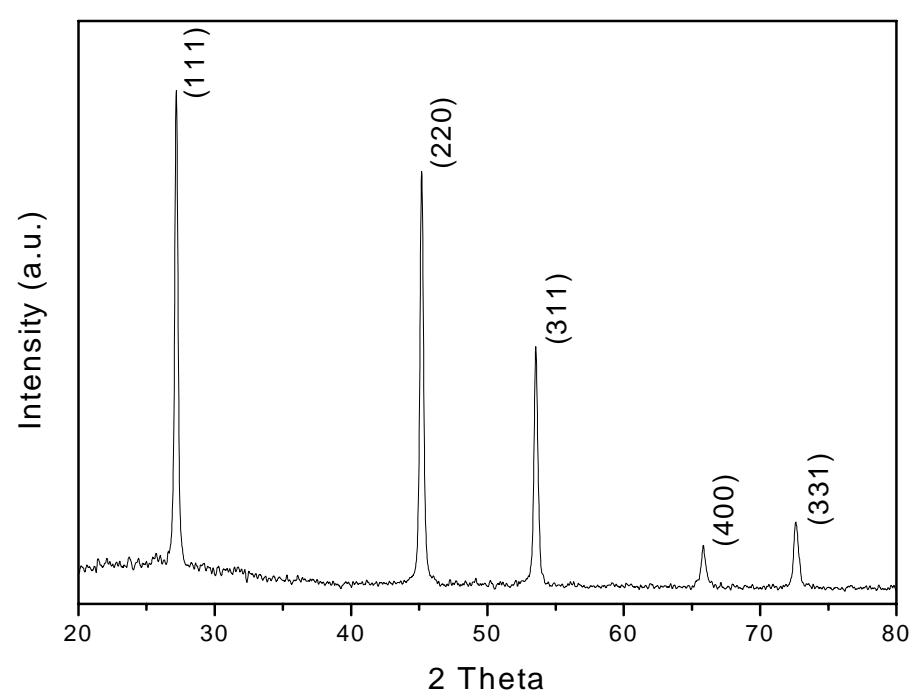


Fig.3 FE-SEM images $\mathrm{ZnO}$ nanorods or nanowires grown on the surface of $\mathrm{ZnSe}$ particles at various temperatures (a) $550^{\circ} \mathrm{C}$, (b) $600^{\circ} \mathrm{C}$, (c) $650^{\circ} \mathrm{C}$, and (d) $700^{\circ} \mathrm{C}$ for 60mins with the ratio of $\mathrm{Zn}: \mathrm{Se}$ as 1:1.
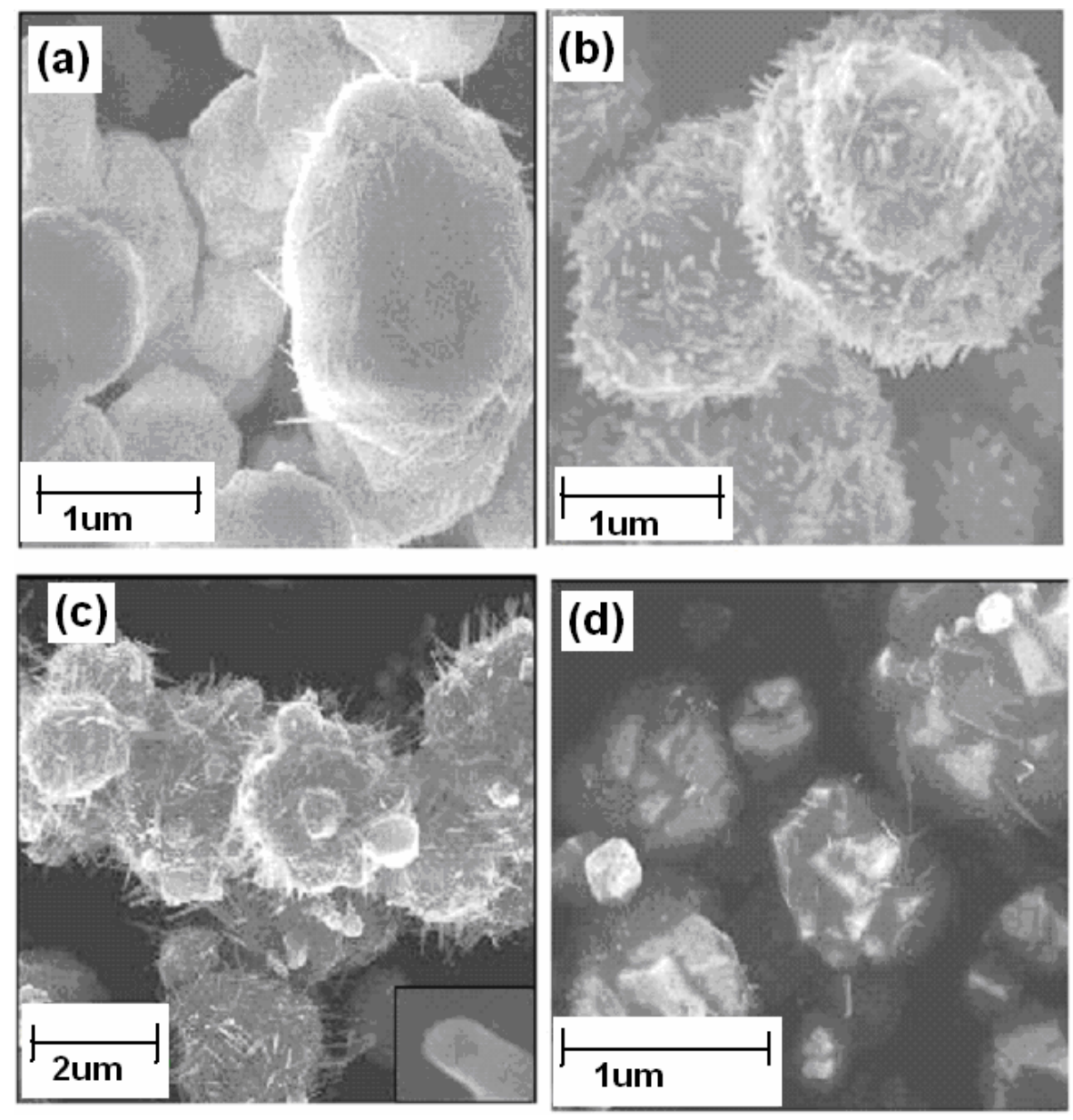
Fig.4 FE-SEM of sample prepared at $650^{\circ} \mathrm{C}$ with different growth time: (a) $15 \mathrm{mins}$, (b) 30mins, (c) 120mins. The ratio of $\mathrm{Zn}: \mathrm{Se}$ is 1:1.
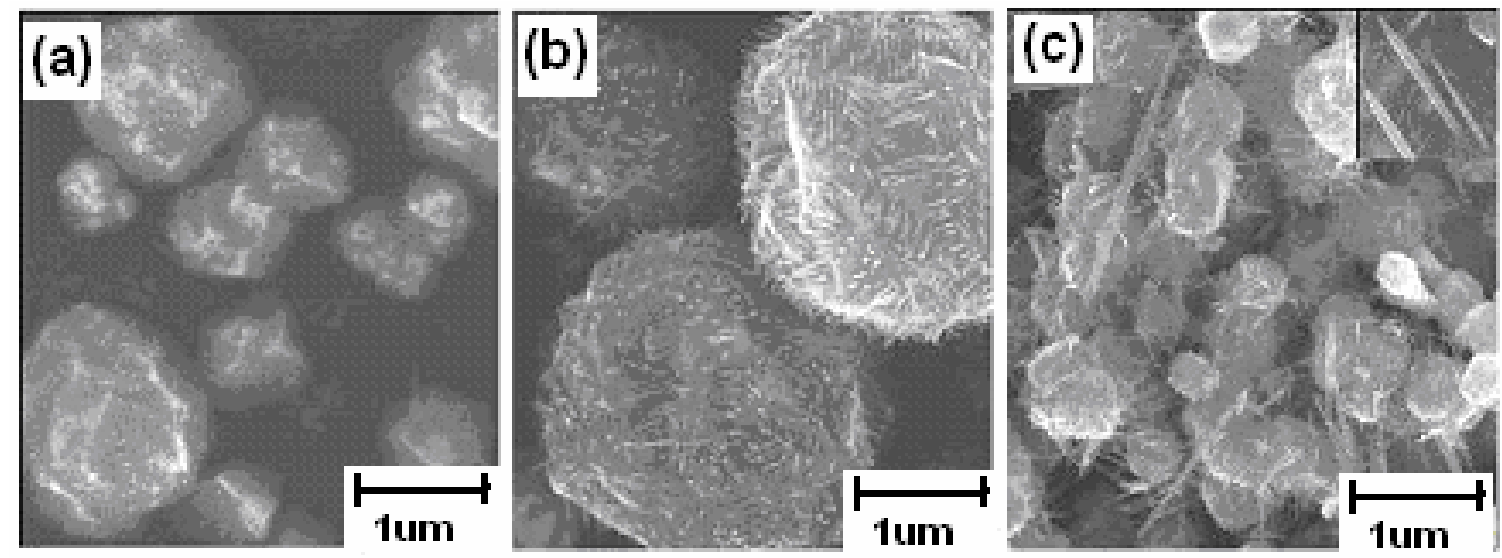
Fig.5 (a) EDS of nanorods, corresponding to circle A in figure (d), (b) EDS of particle, corresponding to circle B in figure (d), (c) HRTEM image of nanorods with the growth direction of [0001]. The inset is the corresponding Fourier transform, (d) The TEM image of the sample prepared at $650^{\circ} \mathrm{C}$ for $60 \mathrm{mins}$. The ratio of $\mathrm{Zn}: \mathrm{Se}$ is about $1: 1$.




Fig. 6 FE-SEM image of sample prepared at $650^{\circ} \mathrm{C}$ for $60 \mathrm{mins}$ with different $\mathrm{Zn}$ :Se ratio:

(a) 2:1, (b) 1:1, (c) 1:5, (d) mixing carbon with $\mathrm{Zn}$. The other parameters are kept constant.
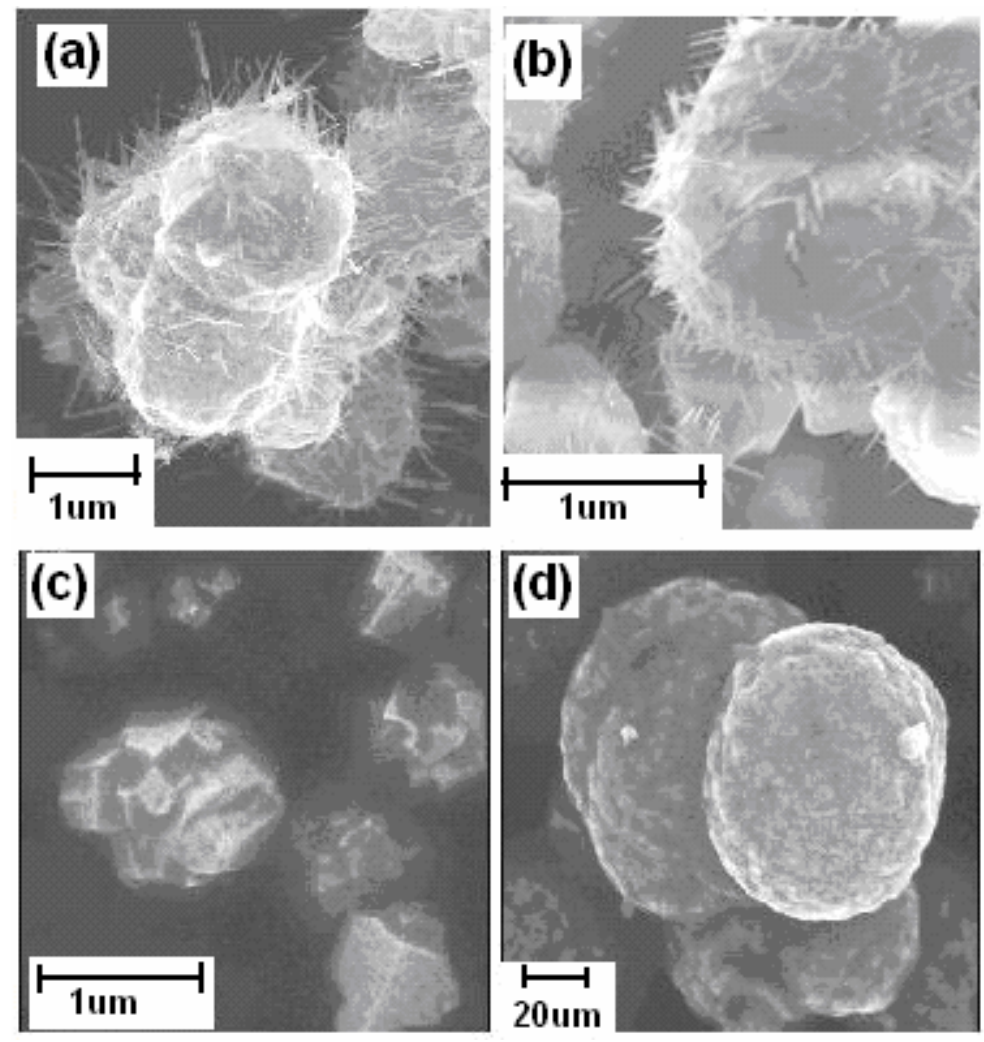
Fig.7 FE-SEM image of sample collected from the inner-wall of crucible and the $\mathrm{Al}_{2} \mathrm{O}_{3}$ substrate in the downstream of the $\mathrm{Zn}$ crucible. The sample is prepared at $650^{\circ} \mathrm{C}$ for $60 \mathrm{mins}$ and the ratio of $\mathrm{Zn}: \mathrm{Se}$ is $1: 1$.
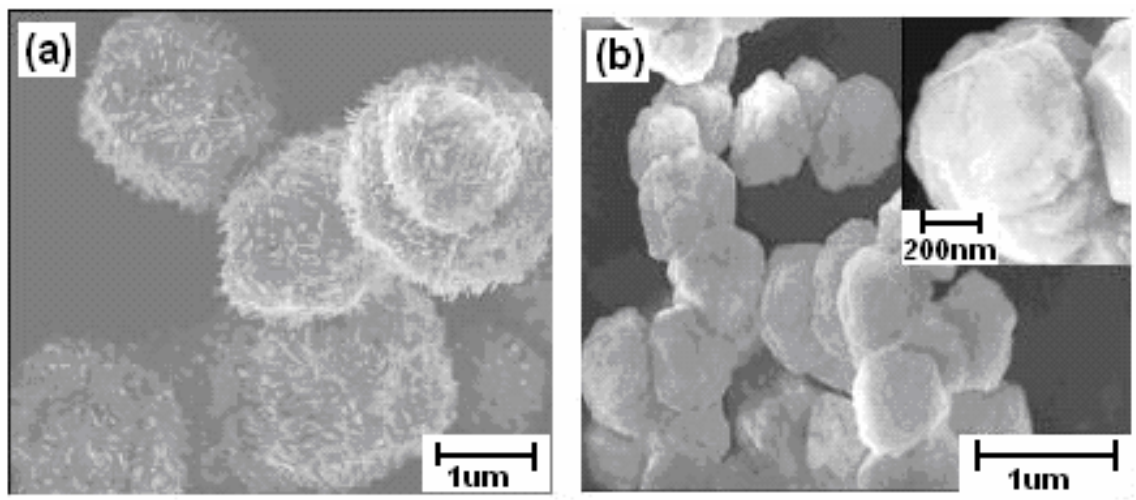
Fig.8 PL at $20 \mathrm{~K}$ of the sample prepared at $650^{\circ} \mathrm{C}$ for $60 \mathrm{~min}$ with different $\mathrm{Zn}$ :Se ratios at $20 \mathrm{~K}$ temperature: (a) 1:5, (b) 1:2, (c):1:1.

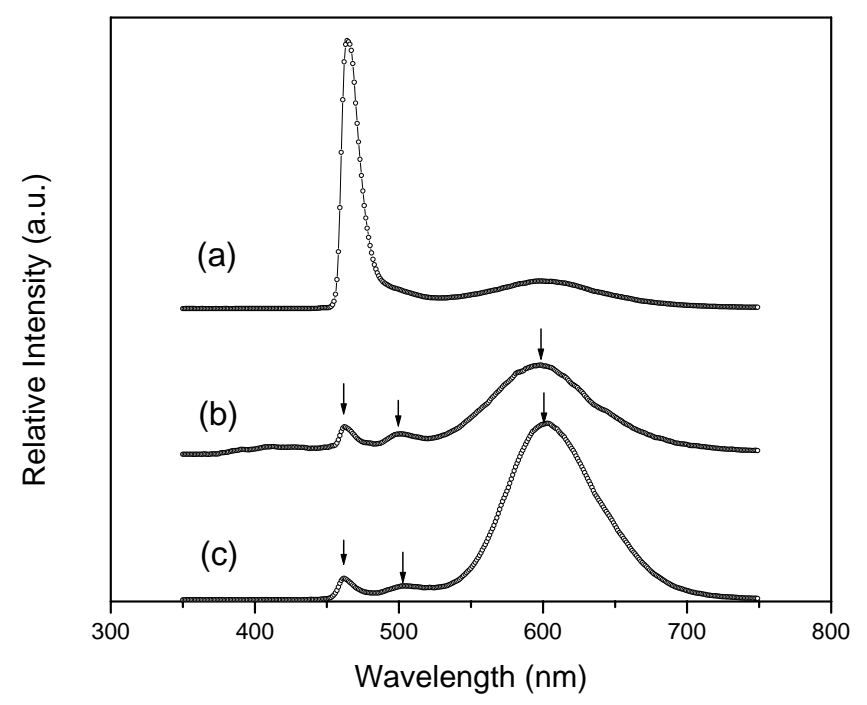

